\title{
A Point Mutation in the Two-Component Histidine Kinase BcOS-1 Gene Confers Dicarboximide Resistance in Field Isolates of Botrytis cinerea
}

\author{
Michiyo Oshima, Makoto Fujimura, Shinpei Banno, Chigusa Hashimoto, \\ Takayuki Motoyama, Akihiko Ichiishi, and Isamu Yamaguchi
}

First, second, third, fourth, and sixth authors: Faculty of Life Science, University of Toyo, Itakura, Oura-gun 374-0193, Japan; and fifth and seventh authors: Plant Science Center, RIKEN, 2-1 Hirosawa, Wako 351-0198, Japan.

Accepted for publication 24 September 2001.

\begin{abstract}
Oshima, M., Fujimura, M., Banno, S., Hashimoto, C., Motoyama, T., Ichiishi, A., and Yamaguchi, I. 2002. A point mutation in the twocomponent histidine kinase $B c O S-1$ gene confers dicarboximide resistance in field isolates of Botrytis cinerea. Phytopathology 92:75-80.

Partial DNA fragments of Botrytis cinerea field isolates encoding the putative osmosensor histidine kinase gene $(B c O S 1)$ were cloned by polymerase chain reaction amplification and the predicted amino acid sequences were compared between dicarboximide-sensitive and resistant field isolates. The predicted $\mathrm{BcOS} 1 \mathrm{p}$ is highly homologous to osmosensor histidine kinase OS1p from Neurospora crassa including the N-

resulted in an amino acid substitution in the predicted protein. In these resistant isolates, codon 86 of the second repeat, which encodes an isoleucine residue in sensitive strains, was converted to a codon for serine. The mutation of Botrytis field resistant isolates was located on the second unit of tandem amino acid repeats of BcOS1p, whereas the point mutations of the fifth repeat of OS1p confer resistance to both dicarboximides and phenylpyrroles and also osmotic sensitivity in Neurospora crassa. These results suggest that an amino acid substitution within the second repeat of $\mathrm{BcOS} 1 \mathrm{p}$ is responsible for phenotypes of field resistant isolates (resistant to dicarboximides but sensitive to phenylpyrroles, and normal osmotic sensitivity) in B. cinerea.
\end{abstract} terminal six tandem repeats of approximately 90 amino acids. Four dicarboximide-resistant isolates of $B$. cinerea $(\mathrm{Bc}-19, \mathrm{Bc}-45, \mathrm{Bc}-682$, and $\mathrm{Bc}-\mathrm{RKR}$ ) contained a single base pair mutation in their $\mathrm{BcOS}$ 1 gene that
Additional keywords: fungicide, glycerol, two-component signal transduction.
Gray mold, caused by Botrytis cinerea, is an economically important disease in many kinds of vegetables, grapes, and flower crops. The dicarboximide fungicides, iprodione and procymidone, are used to control $B$. cinerea (25). However, the spread of $B$. cinerea strains resistant to dicarboximides has greatly reduced the usefulness of the chemicals in many countries $(4,15,16)$. Despite many years of investigation, the mechanism of dicarboximide resistance in field isolates of $B$. cinerea is not known yet (5). The phenylpyrrole fungicides, such as fludioxonil and fenpiclonil, are a new class of fungicides with chemical structures quite different from those of the dicarboximides $(9,22)$. However, the dicarboximides and phenylpyrroles induce similar morphological changes of the germination tubes, and their fungicidal toxicity is reverted by piperonyl butoxide and $\alpha$-tocopherol in $B$. cinerea and other fungi $(8,18)$. These fungicides stimulate glycerol synthesis in the mycelium of Neurospora crassa $(8,14,24)$. Under laboratory conditions, dicarboximides easily select resistant strains in many kinds of fungi including $B$. cinerea. In general, most dicarboximide-resistant laboratory mutants acquire high resistance not only to dicarboximides but also to aromatic hydrocarbons and phenylpyrroles, and they are hypersensitive to osmotic stress $(3,11,17)$. However, high-level resistant strains of $B$. cinerea have seldom been obtained in the field. Only moderately resistant strains without osmotic-sensitive phenotypes are recovered from the field, causing difficulties with disease control $(4,17)$. In addition, dicarboximide-resistant field isolates of $B$. cinerea show cross-resistance to aromatic hydrocarbons but not to phenylpyrroles $(9,18)$. Thus, fludioxonil controls gray mold effectively even in dicar-

Corresponding author: M. Fujimura; E-mail address: fujimura@itakura.toyo.ac.jp

Publication no. P-2001-1102-01R

(C) 2002 The American Phytopathological Society boximide-resistant fields (9). These observations suggest that the resistance mechanism of field isolates differs from that of laboratory isolates.

Faretra and Pollastro have isolated and characterized phenylpyrrole-resistant mutants from $B$. cinerea (6). Genetic analysis indicates that most mutants resistant to phenylpyrroles are caused by the mutations at the Dafl locus responsible for dicarboximide field resistance. Their results suggest that Dafl confers phenotypes of both field resistance and laboratory resistance in $B$. cinerea. The Dafl gene is polymorphic; at least five classes of alleles have been identified for their effects on phenotype response to dicarboximides and phenylpyrroles in $B$. cinerea. Similar results were published by Hilber et al. (13).

We have a working hypothesis that Dafl, which confers the dicarboximide resistance in field isolates of $B$. cinerea, might be a homologue of the os- 1 gene of Neurospora crassa. In Neurospora crassa, osmotic-sensitive mutants, os-1,os-2,os-4, and $o s-5$, are resistant to dicarboximides, aromatic hydrocarbons, and phenylpyrroles $(8,11)$. Among them, only the os- 1 gene of Neurospora crassa is as highly polymorphic as the Dafl gene of B. cinerea (7). All os mutants other than the os- 1 strains are highly resistant to fungicides including phenylpyrroles, and their phenotypes are similar to each other. In contrast, some os- 1 mutant alleles of Neurospora crassa remain sensitive to fludioxonil. In addition, osmotic sensitivity in $o s-1$ mutants is not directly linked with fungicide resistance. All os- 1 mutants are sensitive to osmotic stress, because they have been isolated as osmotic-sensitive mutants but not as dicarboximide-resistant mutants. Thus, it might be possible that specific mutations within the $o s-1$ gene confer the field resistant phenotype. Furthermore, most mutations in laboratory resistant isolates of B. cinerea are mapped on the Dafl locus (6). Similarly, among the $o s$ mutants, $o s-1$ mutants are most easily obtained as dicarboximide-resistant mutants (10). 
The $o s-1$ gene encodes a protein with homology to twocomponent histidine kinase $(1,29)$. This protein is involved in the osmotic signal transduction pathway and needed for adaptation to high osmolarity, although the kinase activity of the $o s-1$ gene product (OS1p) has not been established yet. Two-component histidine kinase SLN1p acts as osmosensor in Saccharomyces cerevisiae $(12,20,26)$. However, N-terminal region of OS1p is quite different from that of SLN1p. OS1p has six repeats of about 90 amino acids at the N-terminal domain, the function of which was unknown. In our previous work, we identified the $o s-1 \mathrm{mu}-$ tations as conferring fungicide resistance and osmotic sensitivity (23). The null mutation of the os- 1 gene conferred high resistance to fungicides. In contrast, single amino acid substitutions on the fifth unit of six tandem repeats of OS1p conferred high sensitivity to osmotic stress but low resistance to fungicides.

In this work, we cloned the $o s-1$ homologue gene ( $\mathrm{BCOS} 1$ ) from several field isolates of $B$. cinerea and compared their sequences to clarify the possibility that $\mathrm{BcOS1}$ gene mutations are responsible for field resistance to dicarboximides in $B$. cinerea.

\section{MATERIALS AND METHODS}

Strains, growth conditions, and antifungal assay. $B$. cinerea strains, dicarboximide-sensitive isolates (Bc-16, Bc-56, Bc-RKS, and Bc-BYS1), and dicarboximide-resistant isolates (Bc-19, Bc$45, \mathrm{Bc}-682$, and $\mathrm{Bc}-\mathrm{RKR}$ ) were obtained from several fields in Japan (Table 1). Strains Bc-SMX and Bc-ROV were selected on medium containing dicarboximide fungicides after UV light irradiation from strains $\mathrm{Bc}-16$ and $\mathrm{Bc}-\mathrm{RKS}$, respectively. $B$. cinerea was maintained on potato dextrose agar (PDA) medium at $18^{\circ} \mathrm{C}$ under black light blue (BLB) light (FL20S, $20 \mathrm{~W}$; Toshiba Co., Tokyo, Japan). To determine sensitivity to fungicides and osmotic stress, mycelial disks were inoculated on PDA containing fungicides or $\mathrm{NaCl}$ in petri dishes and cultured at $20^{\circ} \mathrm{C}$ for 3 days. The mean colony diameter minus the diameter of the inoculation disk was measured and expressed as the percentage of the mean colony diameter of untreated control. Fifty percent effective dose values were determined by regressing the relative growth against the $\log$ of the fungicide concentration. All experiments were repeated twice. To isolate the conidia, the mycelial disks were cultured on VNC medium (Vogel's N medium [31] containing 1.5\% [wt/vol] sucrose, $0.25 \%$ [wt/vol] yeast extract, $0.1 \%$ [wt/vol] casamino acids, $0.5 \%$ [vol/wt] malt extract, and $1.5 \%$ [wt/vol] agar) at $20^{\circ} \mathrm{C}$ for 7 days under BLB light. For suspension culture, conidia $\left(1 \times 10^{6}\right.$ conidia per $\left.\mathrm{ml}\right)$ of $B$. cinerea were inoculated into liquid VNC medium and cultured at $22^{\circ} \mathrm{C}$ for $24 \mathrm{~h}$ with a reciprocal shaker (125 rpm).

For determination of the glycerol content in cells of strains Bc$56, \mathrm{Bc}-45$, and $\mathrm{Bc}-\mathrm{SMX}$, the mycelial suspension was incubated in liquid VNC medium with fungicides or $4 \%$ (wt/vol) $\mathrm{NaCl}$ for $4 \mathrm{~h}$ at $22^{\circ} \mathrm{C}$. The incubated mycelium was then collected by filtration and extensively sonicated in distilled water, and the glycerol in the mycelium was extracted at $80^{\circ} \mathrm{C}$ for $5 \mathrm{~min}$. After centrifugation, the glycerol concentration in the supernatant was measured by the UV-glycerol assay procedure (Roche Diagnostics KK, Tokyo, Japan) (8). After incubation, the cultures were vacuum-filtered and the same mycelia were dried for $24 \mathrm{~h}$ at $105^{\circ} \mathrm{C}$ for dry weight determination.

Cloning of $\mathrm{BcOS1}$ gene of $\boldsymbol{B}$. cinerea. Mycelia of eight field isolates were harvested by filtration and frozen in liquid nitrogen. The genomic DNA of the $B$. cinerea strains was isolated with a fungal DNA miniprep kit (EZNA; Omega Biotek, Doraville, GA) according to the manufacturer's directions. The resultant nucleic acid was used as template for the polymerase chain reaction (PCR) and gene cloning. Two primers, H1A (CA[T/C]GAI[A/T/C]TI[C/A]GIACICC) and N1A (GT[A/G]AA[T/C]TTIAIIGC[A/G]TT) were synthesized as described by Alex et al. (1). These two primers correspond to the $\mathrm{H}$ box consensus $\mathrm{H}(\mathrm{E} / \mathrm{D})(\mathrm{M} / \mathrm{I} / \mathrm{L} / \mathrm{F}) \mathrm{RTP}$ and $\mathrm{N}$ box $\mathrm{NLV}(\mathrm{S} / \mathrm{G}) \mathrm{NA}(\mathrm{I} / \mathrm{V}) \mathrm{KFT}$ of histidine kinase, respectively. Another mix primer, BcOS7 (TGGAARCAYCARAARGCNAAYGAR) was newly designed for the amino acid sequence WKHQKANE, which corresponds to the initial sequence of the first unit in the tandem 90-amino acid repeats of Neurospora crassa os-1 $(1,29)$ and Nectria FIK (U61838). Three primers, BcOS1R (TTGAAGACGGTCCTATAA), BcOS4R (CATACCAATGATACCGTTCAT), and BcOS5 (GAGGCTTTCCAAAAAGCTAT), were also synthesized based on the DNA sequencing of PCR fragments. These primers were used to amplify the genomic DNA from $B$. cinerea. All primers were purified by a Sep-Pak C18 column. The PCR mixtures contained $0.5 \mu \mathrm{M}$ of each primer, $1 \mu \mathrm{g}$ of genomic DNA, and PremixTaq (ExTaq Version, Takara Shuzo Co., Kyoto, Japan) in a total volume of $50 \mu \mathrm{l}$. After being preheated at $95^{\circ} \mathrm{C}$ for $10 \mathrm{~min}$, the reaction mixtures were cycled 20 times at $94^{\circ} \mathrm{C}(1 \mathrm{~min}), 48^{\circ} \mathrm{C}(30 \mathrm{~s})$, followed by a 5-min extension at $72^{\circ} \mathrm{C}$. DNA fragments amplified by PCR reaction were cloned into TA cloning vector (pT7Blue-2; Novagen, Madison, WI).

DNA sequence. An analysis of the DNA sequence was conducted by an auto sequence system (Model 373A; Perkin-Elmer Applied Biosystems, Foster City, CA), the PCR cycle sequencing protocol, and fluorescent dye terminator dideoxynucleotides (Perkin-Elmer Applied Biosystems). The homology and alignment of the nucleotide sequences with those in the gene and protein databases were performed with GENETYX software (Software Development Co., Tokyo, Japan).

Southern blot analysis. Genomic DNA of Bc-56 strain of $B$. cinerea was digested by several restriction enzymes (EcoRI, HindIII, XbaI, XhoI, or EcoRV) and loaded for Southern blot

TABLE 1. Characterization of strains of Botrytis cinerea

\begin{tabular}{|c|c|c|c|c|c|}
\hline \multirow[b]{2}{*}{ Strains } & \multicolumn{2}{|c|}{ Sensitivity to fungicide $(\mu \mathrm{g} / \mathrm{ml})^{\mathrm{a}}$} & \multicolumn{2}{|c|}{ Sensitivity to osmotic stress ${ }^{b}$} & \multirow[b]{2}{*}{ Region of Japan } \\
\hline & Iprodione & Fludioxonil & $4 \% \mathrm{NaCl}$ & $2 \% \mathrm{NaCl}$ & \\
\hline \multicolumn{6}{|c|}{ Dicarboximide sensitive } \\
\hline Bc-16 & 0.3 & 0.01 & 4 & 0 & Hyogo \\
\hline $\mathrm{Bc}-56$ & 0.3 & 0.006 & 13 & 8 & Gunma \\
\hline Bc-RKS & 0.4 & 0.006 & 4 & 0 & Saitama \\
\hline Bc-BYS1 & 0.3 & 0.006 & 32 & 8 & Kochi \\
\hline \multicolumn{6}{|c|}{ Dicarboximide resistant from field } \\
\hline Bc-19 & 3.9 & 0.006 & 35 & 23 & Kagawa \\
\hline $\mathrm{Bc}-45$ & 2.4 & 0.018 & 33 & 12 & Gunma \\
\hline Bc-682 & 5.1 & 0.05 & 40 & 7 & Hyogo \\
\hline Bc-RKR & 1.4 & 0.006 & 35 & 23 & Saitama \\
\hline \multicolumn{6}{|c|}{ Dicarboximide resistant in laboratory } \\
\hline Bc-ROV & $>25$ & $>25$ & 100 & 100 & $\ldots$ \\
\hline Bc-SMX & $>25$ & $>25$ & 96 & 89 & $\ldots$ \\
\hline
\end{tabular}

a Concentration to inhibit radial growth at the $50 \%$ level.

b Percentage of growth inhibition on medium containing $\mathrm{NaCl}$. 
analysis. These enzymes do not digest DNA fragments encoding the amino acid repeats. The DNA was transferred to nylon membranes (Hybond-N+; Amersham Pharmacia Biotech, Tokyo, Japan). PCR fragments encoding the amino acid repeats of the BcOS1 gene were digoxigenin labeled by random priming and hybridized and detected according to the method described in the manufacturer's recommendations (DIG DNA Labeling and Detection Kit; Roche Diagnostics).

Chemicals. Iprodione was purchased from Wako Pure Chemical Industries, Ltd. (Tokyo, Japan). Fludioxonil was contributed by C. Pillonel (Syngenta Crop Protection AG, Basel, Switzerland). The chemicals were stored in the dark at $100 \mathrm{mg} / \mathrm{ml}$ in dimethylsulfoxide at $4^{\circ} \mathrm{C}$.

\section{RESULTS}

Characterization of dicarboximide-resistant field isolates of B. cinerea. Four field isolates, Bc-16, Bc-56, Bc-RKS, and $\mathrm{Bc}-$ BYS1, were sensitive to both iprodione and fludioxonil; their growth was inhibited by iprodione and fludioxonil at a concentrtion of 0.3 to $0.4 \mu \mathrm{g} / \mathrm{ml}$ and 0.01 to $0.006 \mu \mathrm{g} / \mathrm{ml}$, respectively
(Table 1). In comparison, four strains, Bc-19, Bc-45, Bc-682, and $\mathrm{Bc}-\mathrm{RKR}$, grew on medium containing $0.4 \mu \mathrm{g} / \mathrm{ml}$ of iprodione, but their growth was completely inhibited at $25 \mu \mathrm{g} / \mathrm{ml}$, indicating moderate resistance to iprodione. All the dicarboximide field resistant isolates tested were sensitive to fludioxonil. In contrast, two mutants, Bc-ROV and Bc-SMX, that were isolated in our laboratory were highly resistant to both iprodione and fludioxonil. In addition, the growth of these two laboratory mutants was inhibited even on medium containing $2 \%$ (wt/vol) $\mathrm{NaCl}$, whereas the field isolates did not exhibit such high osmotic sensitivity. On medium containing $4 \%$ (wt/vol) $\mathrm{NaCl}$, field resistant isolates were slightly more sensitive to osmotic stress than the sensitive ones, except for BcBYS1 isolate. Although these field strains were collected from different areas in Japan, the phenotypes of the resistant strains were very similar.

Glycerol accumulation induced by iprodione and fludioxonil. Induction of glycerol synthesis was observed in Bc-56, the sensitive strain of $B$. cinerea, through the treatment of iprodione, even at $1 \mu \mathrm{g} / \mathrm{ml}$. The resistant field isolate Bc-45 did not accumulate glycerol in the medium containing $1 \mu \mathrm{g}$ of iprodione per $\mathrm{ml}$, but stimulation of glycerol synthesis did occur at a higher concen-

A
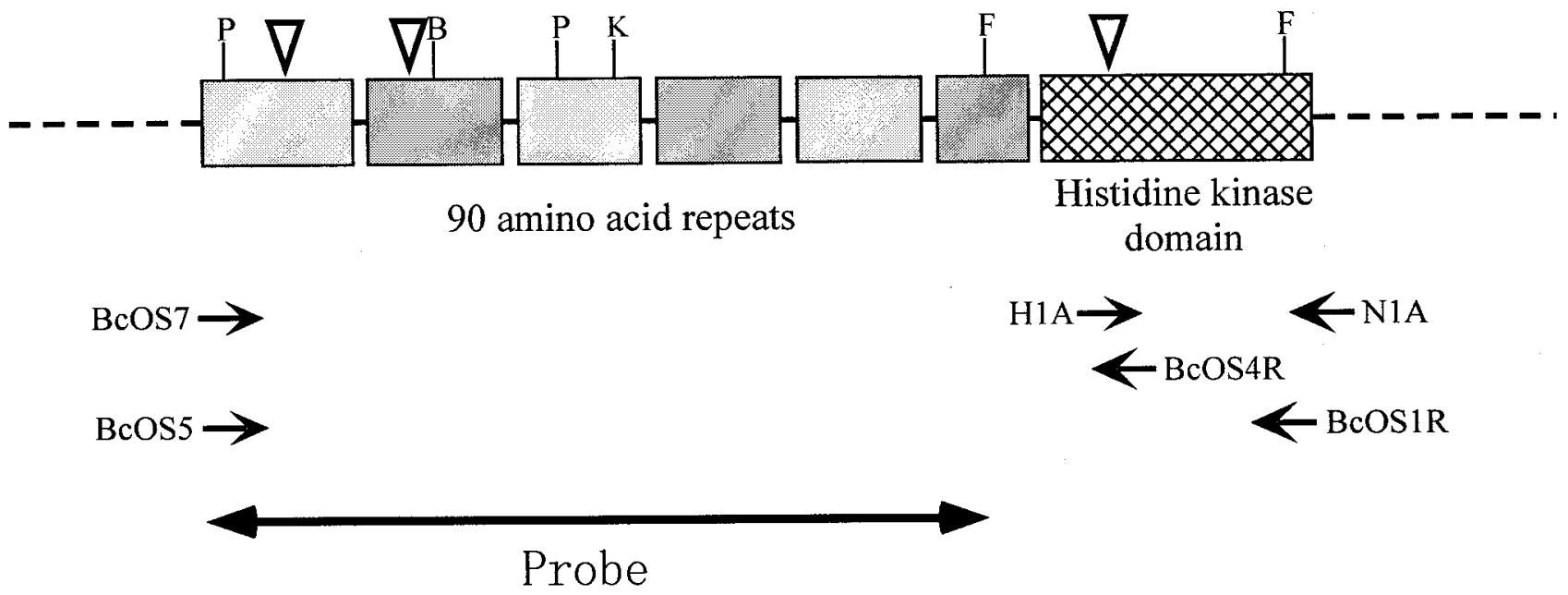

B

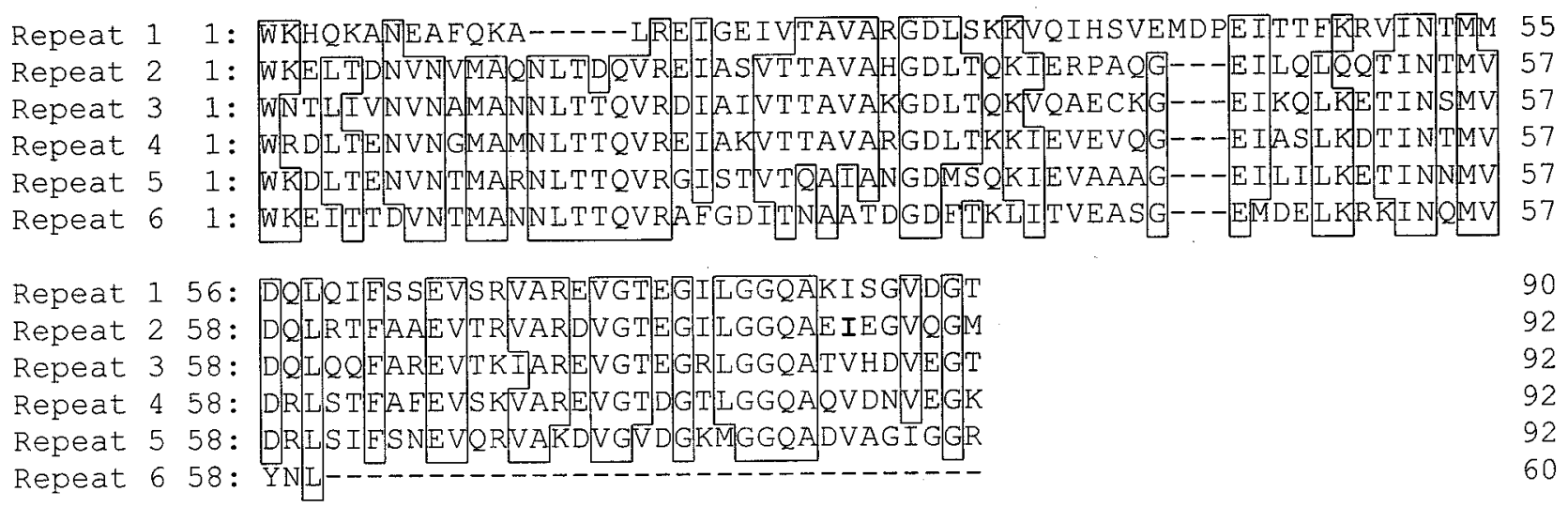

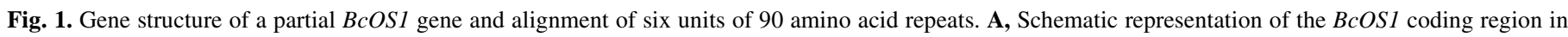

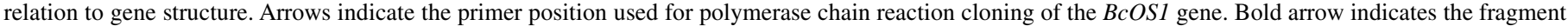

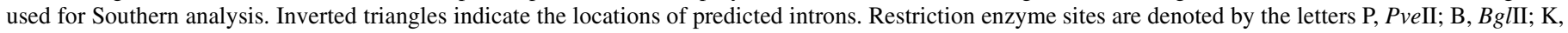

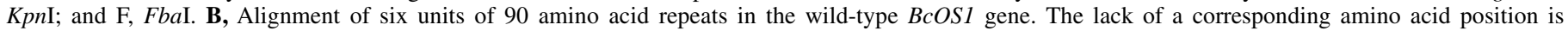
indicated by hyphens. Sites of amino acid substitutions of BcOS1p are written in bold. 
tration of iprodione $(25 \mu \mathrm{g} / \mathrm{ml})$. Fludioxonil induced the glycerol accumulation in both field isolates at concentration of $0.1 \mu \mathrm{g} / \mathrm{ml}$. Conversely, both iprodione and fludioxonil did not stimulate glycerol synthesis in resistant laboratory isolate Bc-SMX at $25 \mu \mathrm{g} / \mathrm{ml}$. In response to $4 \%$ (wt $/ \mathrm{vol}$ ) $\mathrm{NaCl}$, both $\mathrm{Bc}-56$ and $\mathrm{Bc}-45$ strains accumulated glycerol at similar levels, whereas the laboratory resistant Bc-SMX strain accumulated less glycerol.

PCR cloning of two-component histidine kinase $\mathrm{BcOS1}$ gene. Genomic DNA of the Bc-56 strain was isolated and used for PCR cloning of the $o s-1$ homologue gene $(B c O S 1)$ with primers H1A and N1A. The amplification products, approximately $0.4 \mathrm{~kb}$ of DNA fragments, were cloned and sequenced. The deduced amino acid sequence of the partial putative histidine kinase showed high homology to that of Neurospora crassa OS1p. Based on the sequencing result of kinase domain, we designed two primers, $\mathrm{BcOS} 1 \mathrm{R}$ and $\mathrm{BcOS} 4 \mathrm{R}$, to serve as the reverse primers to clone the $\mathrm{N}$-terminal region containing the amino acid repeat domain. A second PCR was conducted with BcOS7 as the forward primer and $\mathrm{BcOS} 1 \mathrm{R}$ as the reverse primer. The resulting PCR products were purified and used for nest PCR with primers BcOS7 and BcOS4R (Fig. 1A). The nested PCR products were cloned and sequenced. The sequencing results revealed that the cloned DNA was highly homologous to the Neurospora crassa os-1 gene. In the same way, we designated a new forward primer, BcOS5, based on the sequencing data, which was completely homologous to the $\mathrm{N}$-terminal of the amino acid repeats of the BcOS1 gene. Finally, we used these two primers, BcOS5 and BcOS1R, which are completely homologous to the $B c O S 1$ gene, and cloned a partial BcOS1 gene from the Bc-56 strain into pT7Blue-2 as pBcOS56 (Fig. 1A).

Approximately $2.2 \mathrm{~kb}$ of fragment of pBcOS56 was sequenced on both strands. Nucleotide sequence analysis indicated a predict- ed open reading frame of approximately $1.9 \mathrm{~kb}$ that was interrupted by three introns. Introns were deduced by similarity to fungal intron consensus sequences. The predicted introns ranged in size from 61 to 203. The predicted 619 amino acids encoded by the partial BcOS1 gene are very similar to that of OS1p of Neurospora crassa and consists of a domain of six 90-amino-acid repeats and a histidine kinase domain (Fig. 1A). Figure 2 shows an amino acid sequence alignment of BcOS1p with the OS1p of Neurospora crassa (1,29), FIKp of Nectria haematococca (U61838), and COS1p of Candida albicans $(2,21)$. The overall amino acid sequence identity of the cloned region of BcOS1p with those of OS1p, FIKp, and COS1p is approximately 92, 87, and $59 \%$, respectively. In addition, $\operatorname{Sin} 1 \mathrm{p}$ from $S$. cerevisiae shared about $30 \%$ identity (data not shown). BcOS1p contains presumed phosphoryl group acceptor $\mathrm{H}$ in the histidine kinase domain, identical to the motif defined for bacterial and yeast histidine kinase module (Fig. 2). BcOS1p contains a 90-amino-acid motif that is repeated five times, followed by a truncated 60 -amino-acid repeat (Fig. 1B). When the individual repeat units were compared with each other, a high degree of homology was revealed, ranging from 41 to $68 \%$ (Fig. 1B). By Southern blot analysis of EcoRI, HindIII, XbaI, XhoI, or EcoRV-digested genomic DNA of strain Bc-56 probed with the 1.4-kb partial gene fragment (Fig. 1A), we could detect only single signals (data not shown), suggesting that this gene is a single copy gene.

Identification of the point mutation in $\mathrm{BcOS1}$ gene of the dicarboximide-resistant isolates. The nucleotide sequences of the $B C O S 1$ gene fragments isolated from four dicarboximideresistant field strains were determined and compared with those of four dicarboximide-sensitive strains. At least three independent PCR cloning processes were done for each genomic DNA to distinguish the original mutations from possible PCR mutations.

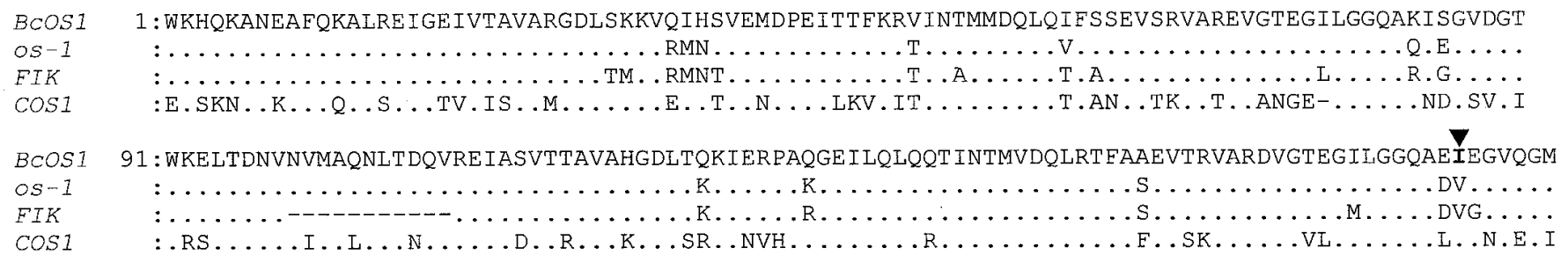

BCOSI $183:$ WNTLIVNVNAMANNLTTQVRDTAIVTTAVAKGDLTQKVQAECKGEIKQLKET INSMVDQLQQFAREVTKIAREVGTEGRIGGQATVHDVEGT

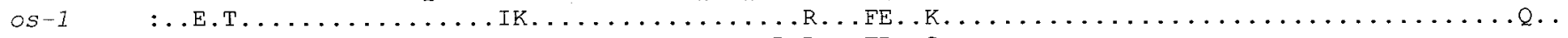

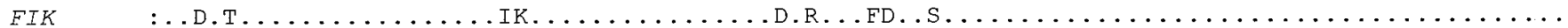

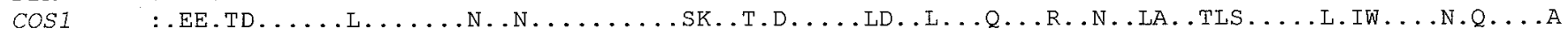

BCOSI 275 : WRDLTENVNGMAMNLTTQVREIAKVTTAVARGDLTKKIEVEVQGEIASLKDT INTMVDRLSTEAFEVSKVAREVGTDGTLGGQAQVDNVEGK

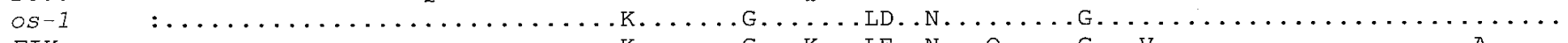

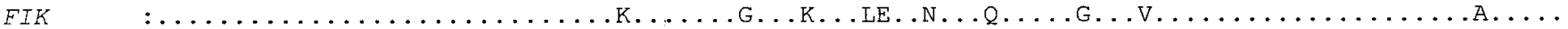

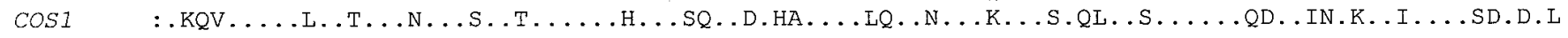

BCOSI $367:$ WKDITENVNTMARNITTQVRGISTVTQAIANGDMSQKIEVAAAGEILIJKETINNMVDRLSIESNEVQRVAKDVGVDGKMGGQADVAGIGGR

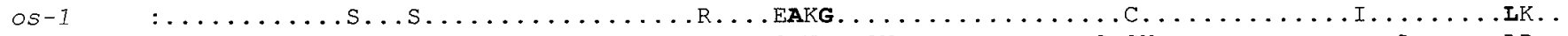

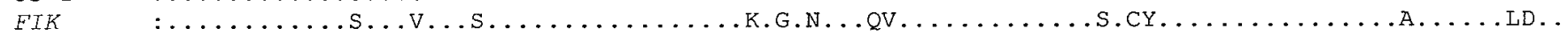

$\cos 1$

BCOS1 459:WKEITTDVNTMANNLTTQVRAFGDITNAATDGDETKLITVEASGEMDELKRKINQMVYNLRDSIQRNTIAREAȦEFANRTKSEFLANMSHEI

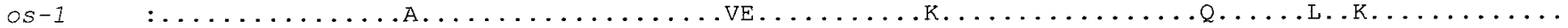

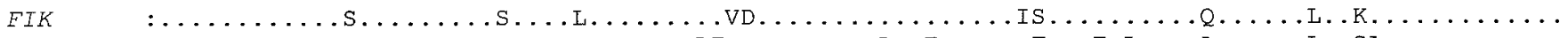

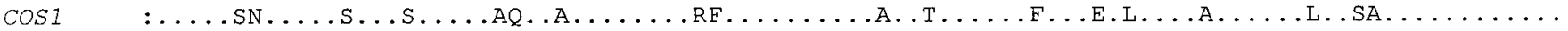

BCOS1 551 :RTPMNGIIGMTQLTLDTDLTQYQREMLNIVHNLANSLLTIIDDILDLSKIEANRMIMEEIPYTLIGTVF

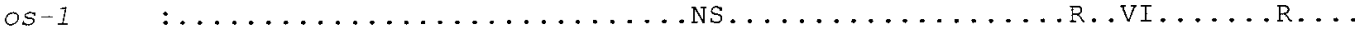

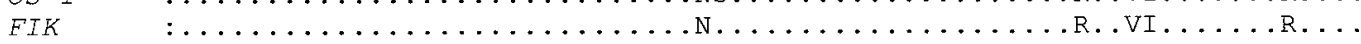

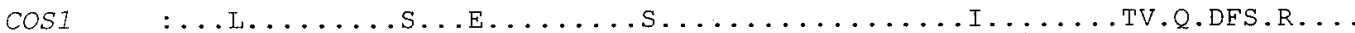

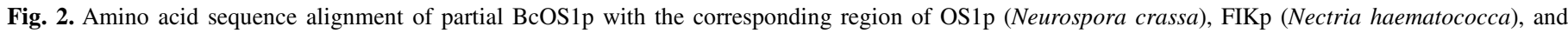

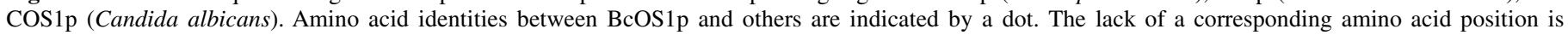

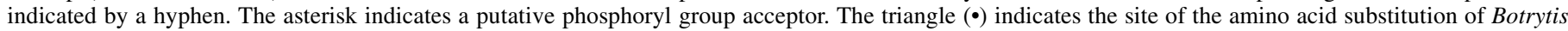
BcOS1p. Sites of amino acid substitutions of Neurospora crassa OS1p are written in bold (23). 
In strains Bc-19, Bc-45, Bc-682, and Bc-RKR, a T-to-G transition occurred at codon 86 of the second amino acid repeat (Table 2), resulting in a serine (AGC) being substituted for isoleucine (ATC). The amino acid isoleucine at codon 86 was conserved in all strains sensitive to dicarboximides. This amino acid change was located on the second unit of six tandem repeats of 90 amino acids at the N-terminal of BcOS1p. Alignment of the second unit of BcOS1p with OS1p, FIKp, and COS1 indicates that the amino acid at codon 86 was restricted in isoleucine or valine (Fig. 2). A comparison of the amino acid sequence in the second unit with those in other units of $\mathrm{BcOS} 1 \mathrm{p}$ revealed that the amino acid residue at codon 86 in each unit was restricted in isoleucine or valine (Fig. 1B). These data strongly suggest that the change from isoleucine to serine confers field resistance to dicarboximides in $B$. cinerea.

\section{DISCUSSION}

In $B$. cinerea, the resistant strains isolated from several fields in Japan were moderately resistant to iprodione but sensitive to fludioxonil, and their phenotypes were very similar to each other (Table 1). The strains highly resistant to dicarboximides and phenylpyrroles that were isolated on the medium containing dicarboximides after UV irradiation displayed a clear osmotic-sensitive phenotype on the medium containing $2 \%$ (vol/wt) $\mathrm{NaCl}$. These observations indicate differences between field resistance and laboratory resistance and were consistent with the results previously reported by Leroux et al. (17). Iprodione as well as fludioxonil stimulated glycerol synthesis in the wild-type strains of $B$. cinerea. In response to osmotic stress, the wild-type strain accumulated glycerol probably to counterbalance high external osmolarity. Glycerol accumulation induced by iprodione was not observed in the highly resistant strain (laboratory resistant strain), whereas the moderately resistant strain (field resistant strain) accumulated glycerol only at a high dose of iprodione. That the levels of resistance in Botrytis strains correlate with the stimulation of glycerol synthesis by fungicide treatments suggests that abnormal glycerol accumulation led to cell death. Similar results have been obtained in Neurospora crassa. However, increased glycerol content was not directly linked with the fungal toxicity of dicarboximides and phenylpyrroles, because both fungicides did not induce glycerol biosynthesis in the fungicide-sensitive cut mutant strain of Neurospora crassa (8). These data suggest that dicarboximides and fludioxonil interfere with the osmotic signal transduction pathway, resulting in stimulation of glycerol biosynthesis, but that abnormal glycerol accumulation is not essential for their fungal toxicity.

In this study, we cloned a two-component histidine kinase $B c O S 1$ gene fragment from $B$. cinerea as a homologue of the Neurospora crassa osmosensor os-1 gene. Although the BcOS1 sequence is homologous with the kinase domain of the two-

TABLE 2. Amino acid substitution of BcOS1p in field strains of Botrytis cinerea

\begin{tabular}{lcc}
\hline Strain & $\begin{array}{c}\text { Codon 86 in } \\
\text { second repeat }^{\mathrm{a}}\end{array}$ & $\begin{array}{c}\text { Amino acid } \\
\text { at codon } 86\end{array}$ \\
\hline $\begin{array}{l}\text { Dicarboximide sensitive } \\
\text { Bc-16 }\end{array}$ & ATC & Isoleucine \\
Bc-56 & ATC & Isoleucine \\
Bc-RKS & ATC & Isoleucine \\
Bc-BYS1 & ATC & Isoleucine \\
Dicarboximide resistant & & \\
Bc-19 & AGC & Serine \\
Bc-45 & AGC & Serine \\
Bc-682 & AGC & Serine \\
Bc-RKR & AGC & Serine \\
\hline
\end{tabular}

a 86th Coden in second amino acid repeat of predicted $B c O S 1$ gene product. component signal protein, the $\mathrm{N}$-terminal end of $\mathrm{BcOS} 1 \mathrm{p}$ is quite different from that of Sln $1 \mathrm{p}$ of $S$. cerevisiae. BcOS1p possesses the tandem repeats of 90 amino acids and the putative autophosphorylated histidine residue in the $\mathrm{H}$ box (Fig. 2), as in the filamentous fungal histidine kinase Neurospora OS1p, Nectria FIKp, and Candida COS1p. There was no predicted membranespanning domain in BcOS1p, OS1p, FIKp, and COS1p in the $\mathrm{N}$ terminus, whereas SIn1p contains two. A typical histidine kinase contains an $\mathrm{N}$-terminal input domain and a C-terminal transmitter domain. The input domain of the sensory histidine kinase detects environmental variables and selectively promotes autophosphorylation of a histidine residue within its transmitter domain. These results suggest that $\mathrm{BcOS} 1 \mathrm{p}$ and OS1p regulate osmotic signal transmission in a manner different from that of $\operatorname{Sin} 1 \mathrm{p}$ of $S$. cerevisiae. The repeat unit motif of $\mathrm{BcOS} 1 \mathrm{p}$ and related kinases showed a structural similarity to that of the bacterial histidine kinase Htrlp, with a high probability of forming a coiled-coil structure, a feature that might be important in the transduction of extracellular signals (19).

In comparing the $B C O S 1$ gene of the dicarboximide-resistant isolates with those of the sensitive ones, we found a single amino acid substitution in the second unit of tandem amino acid repeats of BcOS1p. In four resistant field isolates, codon 86 of the second repeat was substituted with serine for isoleucine. Amino acid change from isoleucine (hydrophobic amino acid) to serine (hydrophilic amino acid) in field resistant strains is predicted to affect the function of the amino acid repeat domain. The 86th codon of each amino acid repeat of BcOS1p was restricted in isoleucine or valine (Fig. 1B). A comparison of the BcOS1p with other os- 1 homologue proteins revealed a conserved isoleucine or valine in position 86 (Fig. 2), suggesting that there is considerable constraint on this residue. These results strongly suggest that this amino acid substitution of serine for isoleucine is responsible for dicarboximide resistance in the field. A practical diagnostic method of detecting the population of dicarboximide-resistant strains in the field with a DNA probe is now under construction. Preliminary data show that all strains containing a mutation from isoleucine to serine are resistant to dicarboximide without exception. However, some isolates with isoleucine at codon 86 in the second unit are resistant to dicarboximides, suggesting the possibility of other types of resistant strains in the field.

The mutations conferring dicarboximide resistance were limited to codon 86 in the second amino acid repeat of $\mathrm{BcOS} 1 \mathrm{p}$ in the field strains of $B$. cinerea. In contrast, we previously identified the point mutations of Neurospora crassa os- 1 mutant alleles; their mutations were located on the fifth amino acid repeat of OS1p, proline from leucine at codon 89 , valine from alanine at codon 42 , and arginine from glycine at codon 44 (23) (Fig. 2). A possible explanation for the reduced variation in mutations of the field strains is that the mutations in other codons might interfere with the fitness of mutants and impose a selective disadvantage under field conditions. The mutations found in $o s-1$ genes of Neurospora confer not only dicarboximide resistance but also increased sensitivity to osmotic stress. Osmotic sensitivity in laboratory resistant strains possibly affects the stability and virulence in field conditions. Even in the field resistant strains, negative correlations between survival of sclerotia and resistance to dicarboximides are found in $B$. cinerea $(27,28)$. It is known that the population of the resistant isolates decreases rapidly after discontinuous application of dicarboximides (30). These observations suggest that most of the mutations within the $B c O S 1$ gene affect virulence or fitness in $B$. cinerea under field conditions.

\section{ACKNOWLEDGMENTS}

This work was supported in part by a Grant-in-Aid for Scientific Research (1066052) from the Ministry of Education, Science, Sports, and Culture of Japan. We thank C. Pillonel for his gift of fludioxonil. 


\section{LITERATURE CITED}

1. Alex, L., Borkovich, K., and Simon, M. 1996. Hyphal development in Neurospora crassa: Involvement of a two-component histidine kinase. Proc. Natl. Acad. Sci. USA 93:3416-3421.

2. Alex, L., Korch, C., Selitrennikoff, C., and Simon, M. 1998. COS1, a two-component histidine kinase that is involved in hyphal development in the opportunistic pathogen Candida albicans. Proc. Natl. Acad. Sci. USA 95:7069-7073.

3. Beever, R. 1983. Osmotic sensitivity of fungal variants resistant to dicarboximide fungicides. Trans. Br. Mycol. Soc. 80:327-331.

4. Beever, R. E., and Brien, H. M. R. 1983. A survey of resistance to the dicarboximide fungicides in Botrytis cinerea. N. Z. J. Agric. Res. 26:391-400.

5. Edlich, W., and Lyr, H. 1995. Mechanism of action of dicarboximide fungicides. Pages 119-131 in: Modern Selective Fungicides-Properties, Applications, Mechanisms of Action. H. Lyr, ed. Gustav Fischer Verlag, New York

6. Faretra, F., and Pollastro, S. 1993. Isolation, characterization and genetic analysis of laboratory mutants of Botryotinia fuckeliana resistant to the phenylpyrrole fungicide CGA 173506. Mycol. Res. 97:620-624.

7. Fujimura, M., Ochiai, N., Ichiishi, A., Usami, R., Horikoshi, K., and Yamaguchi, I. 2000. Fungicide resistance and osmotic stress sensitivity in os mutants of Neurospora crassa. Pestic. Biochem. Physiol. 67:125133.

8. Fujimura, M., Ochiai, N., Ichiishi, A., Usami, R., Horikoshi, K., and Yamaguchi, I. 2000. Sensitivity to phenylpyrrole fungicides and abnormal glycerol accumulation in os and cut mutant strains of Neurospora crassa. J. Pestic. Sci. 25:31-36.

9. Gehmann, K., Nyfeler, R., Leadbeater, A., Nevill, D., and Sozzi, D. 1990. CGA 173506: A new phenylpyrrole fungicide for broad-spectrum disease control. Proc. Br. Crop Prot. Conf. Pests Dis. 2:399-406.

10. Grindle, M. 1984. Isolation and characterization of vinclozolin resistant mutants of Neurospora crassa. Trans. Br. Mycol. Soc. 82:635-643.

11. Grindle, M., and Temple, W. 1982. Fungicide-resistance of $o s$ mutants of Neurospora crassa. Neurospora Newsl. 29:16-17.

12. Gustin, M. C., Albertyn, J., Alexander, M., and Davenport, K. 1998. MAP kinase pathways in the yeast Saccharomyces cerevisiae. Microbiol. Mol. Biol. Rev. 62:1264-1300.

13. Hilber, U., Schwinn, F., and Schuepp, H. 1995. Comparative resistance patterns of fludioxonil and vinclozolin in Botryotinia fuckeliana. J. Phytopathol. 143:423-428.

14. Jespers, A. B. K., Davidse, L. C., and de Waard, M. A. 1993. Biochemical effects of the phenylpyrrole fungicide fenpiclonil in Fusarium sulphureum (Schlecht). Pestic. Biochem. Physiol. 45:116-129.

15. Katan, T. 1982. Resistance to 3, 5-diclorophenyl N-cyclic imide (dicarboximide) fungicides in the gray mold pathogen Botrytis cinerea on protected crops. Plant Pathol. 31:133-141.

16. Leroux, P., and Clerjeau, M. 1985. Resistance of Botrytis cinerea Pars. and Plasmopara veticola (Berk.\&Curt.) to fungicides in French vineyards. Crop Prot. 4:137-160.

17. Leroux, P., Fritz, R., and Gredt, M. 1983. Cross-resistance between 3,5dichlorophenyl cyclic imide fungicides and various aromatic compounds. Pages 79-88 in: Systematische Fungizide und Antifungale Verbindungen. H. Lyr and C. Polter, eds. Akademie-Verlag, Berlin.

18. Leroux, P., Lanen, C., and Fritz, R. 1992. Similarities in the antifungal activities of fenpiclonil, iprodione and tolclofos-metyl against Botrytis cinerea and Fusarium nivale. Pestic. Sci. 36:255-261.

19. Lupas, A., Dyke, M. V., and Stock, J. 1991. Predicting coiled coils from protein sequences. Science 252:1162-1164.

20. Maeda, T., Susannah, M., Wurgler-Murphy, S., and Saito, H. 1994. A two-component system that regulates an osmosensing MAP kinase cascade in yeast. Nature 369:242-245.

21. Nagahashi, S., Mio, T., Ono, N., Yamada-Okabe, T., Arisawa, M., Bussey, H., and Yamada-Okabe, H. 1998. Isolation of CaSLN1 and CaNIK1, the genes for osmosensing histidine kinase homologues, from the pathogenic fungus Candida albicans. Microbiology 144:425-432.

22. Nevill, D., Nyfeler, R., and Sozzi, D. 1988. CGA 142705: A novel fungicide for seed treatment. Proc. Br. Crop Prot. Conf. Pests Dis. 1:6572.

23. Ochiai, N., Fujimura, M., Motoyama, T., Ichiishi, A., Usami, R., Horikoshi, K., and Yamaguchi, I. 2001. Characterization of mutations in the two-component histidine kinase gene that confer fludioxonil resistance and osmotic sensitivity in the os-1 mutants of Neurospora crassa. Pest Manag. Sci. 57:437-442.

24. Pillonel, C., and Meyer, T. 1997. Effect of phenylpyrroles on glycerol accumulation and protein kinase activity of Neurospora crassa. Pestic. Sci. 49:229-236.

25. Pommer, E., and Lorenz, G. 1995. Dicarboximide fungicides. Pages 99118 in: Modern Selective Fungicides-Properties, Applications, Mechanisms of Action. H. Lyr, ed. Gustav Fischer Verlag, New York.

26. Posas, F., and Saito, H. 1997. Osmotic activation of the HOG MAPK pathway via Ste11p MAPKKK: Scaffold role of Pbs2p MAPKK. Science 276:1702-1705.

27. Raposo, R., Delcan, J., Gomez, V., and Melgarejo, P. 1996. Distribution and fitness of isolates of Botrytis cinerea with multiple fungicide resistance in Spanish greenhouses. Plant Pathol. 45:497-505.

28. Raposo, R., Gomez, V., Urrutia, T., and Melgarejo, P. 2000. Fitness of Botrytis cinerea associated with dicarboximide resistance. Phytopathology 90:1246-1249.

29. Schumacher, M., Enderlin, C., and Selitrennikoff, C. 1997. The osmotic1 locus of Neurospora crassa encodes a putative histidine kinase similar to osmosensors of bacteria and yeast. Curr. Microbiol. 34:340-347.

30. Staub, T. 1991. Fungicide resistance: Practical experience with antiresistance strategies and the role of integrated use. Annu. Rev. Phytopathol. 29:421-442.

31. Vogel, H. J. 1964. Distribution of lysine pathways among fungi: Evolutionary implications. Am. Nat. 98:435-446. 